\title{
Sensorimotor Gating is Associated with CHRNA3 Polymorphisms in Schizophrenia and Healthy Volunteers
}

\author{
Nadine Petrovsky ${ }^{1,6}$, Boris B Quednow*,2,6, Ulrich Ettinger ${ }^{3}$, Anne Schmechtig ${ }^{4}$, Rainald Mössner', \\ David A Collier ${ }^{5}$, Kai-Uwe Kühn', Wolfgang Maier', Michael Wagner' and Veena Kumari ${ }^{4}$ \\ 'Department of Psychiatry and Psychotherapy, University of Bonn, Bonn, Germany; ${ }^{2}$ Division of Experimental and Clinical Pharmacopsychology, \\ University Hospital of Psychiatry, University of Zurich, Zurich, Switzerland; ${ }^{3}$ Department of Psychiatry and Department of Psychology, \\ Ludwig-Maximilians University Munich, Munich, Germany; ${ }^{4}$ Department of Psychology, Institute of Psychiatry, King's College London, London, UK; \\ ${ }^{5}$ Social, Genetic and Developmental Psychiatry Centre, Institute of Psychiatry, King's College London, London, UK
}

Attentional gating deficits, commonly measured by prepulse inhibition (PPI) of the acoustic startle response (ASR), have been established as an endophenotype of schizophrenia. Prepulse inhibition is heritable and has been associated with polymorphisms in serotonin and dopamine system genes. Prepulse inhibition can be enhanced by nicotine, and therefore it has been proposed that schizophrenia patients smoke to ameliorate their early attentional deficits. The PPI-enhancing effects of nicotine in rodents are strain dependent, suggesting a genetic contribution to PPI within the nicotinic acetylcholine receptor (nAChR) system. Recent human genetic studies also imply that tobacco dependence is affected by polymorphisms in the $\alpha 3 / \alpha 5$ subunits of the nAChR (CHRNA3/CHRNA5) gene cluster. We, therefore, investigated the impact of two common CHRNA3 polymorphisms (rs I05I730/rs I 317286 ) on PPI, startle reactivity, and habituation of the ASR in two independent samples of 107 healthy British volunteers and 73 schizophrenia patients hailing from Germany. In both samples, PPI was influenced by both CHRNA3 polymorphisms (combined p-value $=0.0027$ ), which were strongly linked. Moreover, CHRNA3 genotype was associated with chronicity, treatment, and negative symptoms in the schizophrenia sample. These results suggest that sensorimotor gating is influenced by variations of the CHRNA3 gene, which might also have an impact on the course and severity of schizophrenia.

Neuropsychopharmacology (2010) 35, 1429-1439; doi:10.1038/npp.2010.12; published online 10 March 2010

Keywords: prepulse inhibition; sensorimotor gating; CHRNA3; nicotinic acetylcholine receptor; rs I05 I 730; schizophrenia

\section{INTRODUCTION}

Prepulse inhibition (PPI) of the acoustic startle response is defined as the suppression of the startle reflex that occurs when a relatively weak and non-startling sensory event (the prepulse) is presented $30-500 \mathrm{~ms}$ before a strong startleeliciting stimulus (the pulse; Graham, 1975). The phenomenon, PPI, has been firmly established as an operational measure of sensorimotor gating because it is thought to regulate sensory input by filtering or 'gating out' excess or irrelevant stimuli to prevent sensory information overflow (Braff et al, 2001). Prepulse inhibition is regulated by a cortico-striato-pallido pontine (CSPP) circuitry including frontal and mediotemporal brain regions, the ventral striatum, the ventral pallidum, and pontine regions of the brainstem (Koch, 1999; Swerdlow et al, 2001). Lesion and

\footnotetext{
*Correspondence: Dr BB Quednow, Division of Experimental and Clinical Pharmacopsychology, University Hospital of Psychiatry, Lenggstrasse 31, CH-8032 Zurich, Switzerland, Tel: +4I 44384 2777, Fax: +4I 44384 2499, E-mail: quednow@bli.uzh.ch

${ }^{6}$ These authors contributed equally to this work.

Received 24 September 2009; revised 10 December 2009; accepted 14 January 2010
}

pharmacological challenge studies in rodents have revealed that dopamine, serotonin, glutamate, and acetylcholine are involved in the mediation of PPI (Geyer et al, 2001; Swerdlow et al, 2001). Recent association studies in healthy humans and schizophrenia patients suggest that genetic variations of the serotonin-2A receptor $\left(5-\mathrm{HT}_{2 \mathrm{~A}} \mathrm{R}\right)$, the catechol-O-methyltransferase (COMT), and the dopamineD3 receptor (DRD3) may all affect PPI (Quednow et al, 2008b, c, 2009; Roussos et al, 2008a, b). However, it is most likely that each of these genetic polymorphisms only explains a fraction of the PPI variance and that further genes, including perhaps genes within the glutamate and acetylcholine system, also contribute to the variant expression of PPI.

Several psychiatric and neurological disorders have been reported to present sensorimotor-gating deficits (for reviews, see Braff et al, 2001; Quednow, 2008) but the most consistent findings are PPI deficits in schizophrenia spectrum disorder (Braff et al, 1978, 1992; Cadenhead et al, 1993, 2000; Kumari et al, 2000; Ludewig et al, 2003; Parwani et al, 2000; Perry et al, 2002; Quednow et al, 2006b; Swerdlow et al, 2006). The findings that PPI is heritable (Anokhin et al, 2003; Greenwood et al, 2007), that it is 
reduced in unaffected relatives of schizophrenia patients (Cadenhead et al, 2000; Kumari et al, 2005b), that it is influenced by polymorphisms within the dopamine and serotonin system (Quednow et al, 2008b, c, 2009; Roussos et al, 2008a,b), and that PPI deficits are present during the prodromal stage, before the clinical diagnosis of schizophrenia (Quednow et al, 2008a), suggested that PPI is an important and valid candidate as an intermediate or endophenotypic marker in genetic studies of schizophrenia (Braff and Freedman, 2002; Gottesman and Gould, 2003).

Studies in humans (Baschnagel and Hawk, 2008; Della Casa et al, 1998; Duncan et al, 2001; Hong et al, 2008; Kumari et al, 1996, 1997) and animals (Acri et al, 1994, 1995; Curzon et al, 1994; Faraday et al, 1999; Schreiber et al, 2002; Spielewoy and Markou, 2004) have shown that the nicotinic acetylcholine receptor ( $\mathrm{nAChR}$ ) agonist, nicotine, enhances PPI. These findings, taken together with the idea that schizophrenia patients have a strongly increased likelihood of smoking (for reviews, see Dalack et al, 1998; Ripoll et al, 2004), have led to the 'self-medication hypothesis' that proposes that schizophrenia patients may attempt to transiently remedy otherwise deficient attentional processes; this effect, however, could vary depending on genetic background (Kumari and Postma, 2005). Prepulse inhibition studies also contribute to the view that neurocognitive dysfunction in schizophrenia could be based on a dysfunctional nAChR system: George et al. (2006) demonstrated that tobacco smoking selectively enhances PPI deficits in schizophrenia and more recently it was also shown that nasally administered nicotine increases PPI in schizophrenia patients and healthy controls (Hong et al, 2008). Interestingly, the PPI-enhancing effects of nicotine in schizophrenia patients could be dose-dependently blocked by the non-competitive and non-selective nAChR antagonist, mecamylamine, which suggests that this effect is mediated through activation of central nAChR (George et al, 2006). Given that mecamylamine antagonizes $\alpha 3 \beta 2$, $\alpha 3 \beta 4, \alpha 4 \beta 2$, and $\alpha 7 \mathrm{nAChRs}$ but that its antagonism at the $\alpha 7$ subunit is not functional (Papke et al, 2001), the PPIincreasing effects of nicotine are likely explained by an activation of $\alpha 3 \beta 2, \alpha 3 \beta 4$, and/or $\alpha 4 \beta 2 \mathrm{nAChRs} \mathrm{(Sacco} \mathrm{et} \mathrm{al,}$ 2005). Moreover, $\alpha 7$ nAChR knock-out mice display normal PPI levels, and neither selective $\alpha 7$ nAChR agonists (GTS-21 and AR-R-17779) nor a selective $\alpha 7 \mathrm{nAChR}$ antagonist (methyllycaconitine) altered PPI level in rodents (Schreiber et al, 2002; Suemaru et al, 2004), making it unlikely that $\alpha 7$ nAChRs significantly contribute to the normal regulation of PPI. At present, it is still unclear whether genetic variation in the nAChR system could have an impact on human PPI. However, the PPI-enhancing effects of nicotine in rodents seem to be strain dependent, which points to a strong genetic modulation of this effect within the nAChR system (Curzon et al, 1994; Faraday et al, 1998, 1999; Schreiber et al, 2002; Spielewoy and Markou, 2004).

Several recent studies have consistently shown that multiple single-nucleotide polymorphisms (SNPs) within the $\alpha 3 / \alpha 5 \mathrm{nAChR}$ subunit (CHRNA3/CHRNA5) gene cluster, on chromosome 15q25.1, are strongly associated with nicotine dependence (Berrettini et al, 2008; Bierut et al, 2008; Caporaso et al, 2009; Saccone et al, 2009). Berrettini et al (2008) observed that 'cigarettes per day' (CPD) was associated with a common haplotype in the CHRNA3/ CHRNA5 gene cluster in three independent populations of European origin totaling about 15000 individuals. In particular, SNPs: rs578776, rs1051730, rs1317286, and rs6495308 were associated with CPD. A recent meta-analysis by Caporaso et al (2009) further supports the idea that diverse SNPs of the CHRNA3 and CHRNA5 genes are associated with CPD, including rs1051730 in CHRNA3 (combined $p$-value $=5 \times 10^{-32}$ ). Furthermore, a meta-analysis of schizophrenia linkage studies suggested that chromosomal region 15q21.3-15q26.1 may harbor illnessassociated genes (Lewis et al, 2003), but presently it is unclear whether there are genetic polymorphisms in the nAChR system, which account for both the vulnerability to schizophrenia and smoking behavior. An altered nAChR system may lead to gating dysfunctions, which could be ameliorated by self-administered nicotine, and may at least explain a portion of the variance for the development of schizophrenia and/or smoking. We therefore assume that certain genetic polymorphisms in $\mathrm{nAChR}$ subunits similarly account for attentional endophenotypes in schizophrenia and nicotine dependence.

On the basis of findings from Berrettini et al (2008) and the meta-analysis by Caporaso et al (2009), we hypothesized that SNPs of the CHRNA3/CHRNA5 gene cluster would have an impact on sensorimotor gating that is disturbed in schizophrenia and enhanced by nicotine. Given that the $\alpha 3$ nAChR might be involved in the reversal of sensorimotorgating deficits in schizophrenia (George et al, 2006), we focused on SNPs of the CHRNA3 gene. We have chosen two of the four SNPs (rs1051730 and rs1317286) that were associated with cigarette smoking in the large study conducted by Berrettini et al (2008) and that displayed the highest minor allele frequencies of approximately 30$40 \%$ in European-ancestry samples (Bierut et al, 2008; International HapMap Consortium, 2003; Saccone et al, 2009). We investigated two independent European Caucasian samples - a sample of 107 healthy volunteers recruited in London, United Kingdom, and a sample of 73 schizophrenia inpatients recruited in Bonn, Germany, to directly test for the replicability of our findings.

\section{MATERIALS AND METHODS}

\section{Participants}

For the first experiment, 107 healthy Caucasian volunteers were recruited through local advertisements in South London, United Kingdom. Participants between 18 and 43 years of age were screened for the exclusion criteria of DSM-IV Axis I disorders using the Structured Clinical Interview for DSM-IV Disorders (SCID-I). Additional exclusion criteria were: a history of head injuries, any known neurological abnormalities or systemic illness with known neurological complication, a first-degree relative with psychosis or obsessive-compulsive disorder, and a history of substance abuse or dependence. Current smoking behavior was assessed using the Fagerström Test for Nicotine Dependence (FTND; Heatherton et al, 1991) and the CPD value.

For the second experiment, 73 schizophrenia inpatients admitted to the psychiatric hospital of the University of 
Bonn, Germany, were considered eligible for the study if the following criteria were met: a diagnosis of schizophrenia according to DSM-IV, age between 18 and 65 years, and Caucasian ethnicity. Patients were excluded if they had a history of head injuries, a neurological disease, a history of substance abuse or dependency, or a severe somatic disease. Every patient was evaluated through SCID-I. Clinical symptoms were measured using the Positive and Negative Syndrome Scale (PANSS; Kay et al, 1992). A total of 14 patients were unmedicated, 12 patients received a typical antipsychotic drug, 43 patients were treated with an atypical antipsychotic drug, 3 received two atypical drugs, and 1 received a typical and an atypical antipsychotic. Moreover, three patients received antidepressants and five were treated with benzodiazepines that were tapered $24 \mathrm{~h}$ before startle testing. Current smoking status was assessed by the question: Do you smoke more than 10 cigarettes per week (yes: smoker/no: non-smoker)?

For both samples, ethical approvals of the local ethics committees were obtained, and all participants provided written informed consent before inclusion into the study.

\section{Genotyping}

In the British healthy volunteers, SNP genotyping assays were run as submicroliter polymerase chain reaction-based assays on Array Tape (http://www.douglasscientific.com) at PreventionGenetics (Marshfield, Wisconsin). For the schizophrenia patients hailing from Germany, SNPs were analyzed by TaqMan assays (Applied Biosystems, Foster City, California). Both procedures are described in detail in Supplementary Material 1.

\section{Startle Response Measurement}

The two samples were assessed with slightly different PPI paradigms. Equipment, set up, PPI testing, and data acquisition and scoring procedures for both have previously been described in detail (London sample: Kumari et al, 2005a; Bonn sample: Quednow et al, 2006a, b).

In the London healthy volunteer sample, each examination began with a 4-min acclimation period of $70-\mathrm{dB}$ background noise that was continued throughout the session. Participants received 49 white-noise sound pulses at an intensity of $115 \mathrm{~dB}$ (duration of $40 \mathrm{~ms}$ ) separated by variable inter-trial intervals (ITIs) between 9 and $23 \mathrm{~s}$ $($ mean $=15 \mathrm{~s})$. In 36 of the trials, the pulse was preceded by a $20-\mathrm{ms}, 85-\mathrm{dB}$ white-noise prepulse with stimulus-onset asynchronies (SOAs) of 30, 60, and $120 \mathrm{~ms}$ (12 trials each). The initial trial was a pulse-alone (PA) trial, which was separated for further analysis. All following trials were presented in a pseudo-randomized order. The entire test session lasted approximately $16 \mathrm{~min}$.

In the Bonn schizophrenia sample, each examination began with a 4-min acclimation period of 70-dB background noise that was continued throughout the session. Participants received 73 white-noise sound pulses at an intensity of $116 \mathrm{~dB}$ (duration of $40 \mathrm{~ms}$ ) separated by variable ITIs between 8 and $22 \mathrm{~s}$ (mean $=15 \mathrm{~s}$ ). In 36 of the trials, the pulse was preceded by a $20-\mathrm{ms}, 86-\mathrm{dB}$ white-noise prepulse with a SOA of $120 \mathrm{~ms}$. The PA initial trial was separated for further analysis. All following trials were presented in a pseudo-randomized order. The entire test session lasted approximately $20 \mathrm{~min}$.

To ensure that PPI was not influenced by smoking withdrawal, smoking ad libitum was permitted before testing in both laboratories (Kumari and Gray, 1999). Trial exclusion and scoring criteria were identical to those used in previous studies (Quednow et al, 2006b). Subjects with response rejections $>50 \%$ were excluded from data analysis (healthy volunteers: $n=3$; schizophrenia patients: $n=2$ ).

\section{Statistical Analysis}

The calculation of the mean percent PPI and the habituation measures (percent habituation and linear gradient coefficient $b$ ) have been described in detail elsewhere (Quednow et al, 2006a, b). For the assessment of startle habituation, PA trials were divided each into four blocks in the British sample and in six blocks in the German sample. Startle reactivity was assessed by the mean amplitude of the first block of PA trials and the mean amplitude of all PA trials.

We did a priori- and post hoc-power analyses of both experiments using $\mathrm{G}^{\star}$ Power 3.0.3 (Faul et al, 2007). The actual power of both experiments ranged from satisfactory to good: Bonn sample $72 \%$; London sample $80 \%$; and total sample $98 \%$ (see Supplementary Table A). All demographic data were analyzed by analysis of variance (ANOVA) with the exception of frequency data. Frequency data were analyzed using $\chi^{2}$ tests. Given that sex (Swerdlow et al, 1997) and smoking (Kumari and Gray, 1999) could affect PPI, these variables were introduced as covariates in analyses of covariance (ANCOVA) of PPI data independent of the statistical significance of the covariates. All other psychophysiological parameters were analyzed through ANOVA. On the basis of significant main effects or interactions, conservative post hoc comparisons according to Bonferroni were performed. The confirmatory statistical comparisons were carried out at a significance level set at $p<0.05$ (two-tailed). Within the Pearson Product-Moment correlation analyses, the significance level was set at $p<0.01$ (two-tailed) to avoid accumulation of $\alpha$-error. Effect size calculations between two groups refer to Cohen's $d$. The Armitage's Trend Test was used to analyze associations between CHRNA3 SNPs and schizophrenia. For a metaanalysis of the genotype effects on psychophysiological parameters across both samples, we used Stouffer's $z$-score method (Whitlock, 2005).

\section{RESULTS}

\section{London Sample (Healthy Volunteers)}

The CHRNA3 rs1051730 and rs1317286 SNPs were in strong linkage disequilibrium $\left(r^{2}=0.967\right)$ and both genotype frequencies were distributed in accordance with HardyWeinberg equilibrium (HWE) (rs1051730: $\chi^{2}(1)=0.09$; $p=0.77 ;$ rs 1317286: $\left.\chi^{2}(1)=0.47 ; p=0.51\right)$. Genotype frequencies were also very similar between the UK and German populations. Given that the rs1051730 and rs1317286 SNPs were in such strong linkage disequilibrium and that their effects on the psychophysiological parameters 
Table I Demographic Data and Psychophysiological Parameters of British Healthy Human Volunteers

\begin{tabular}{|c|c|c|c|c|c|c|c|c|}
\hline CHRNA3 rsI05I730 genotype & TT & TC & CC & Total & $\mathbf{F} / \chi^{2}$ & $d f / d f_{\text {err }}$ & $p$ & $\eta_{p}^{2}$ \\
\hline N & $12(12.5 \%)$ & $40(41.7 \%)$ & $44(45.8 \%)$ & $96(100 \%)$ & & & & \\
\hline Age (years) & $24.6(1.1)$ & $25.6(1.0)$ & $26.7(0.9)$ & $26.0(0.6)$ & 0.80 & 2/95 & 0.45 & 0.02 \\
\hline Years of education & I $6.8(0.9)$ & $16.8(0.4)$ & $17.4(0.6)$ & $17.1(0.3)$ & 0.41 & $2 / 95$ & 0.67 & 0.01 \\
\hline Men (\%) & 50.0 & 47.5 & 47.7 & 47.9 & 0.02 & 2 & 0.99 & - \\
\hline Current smokers (\%) & 16.7 & 25.0 & 25.0 & 24.0 & 0.40 & 2 & 0.82 & - \\
\hline $\begin{array}{l}\text { Fagerström nicotine dependence test } \\
\text { (score; only in smokers) }\end{array}$ & $2.0(2.0), n=2$ & $1.6(0.7), n=10$ & $2.0(0.7), n=11$ & $1.8(0.5), n=23$ & 0.09 & $2 / 22$ & 0.92 & 0.01 \\
\hline $\begin{array}{l}\text { First block, amplitude of pulse-alone } \\
\text { trials (arbitrary units) }\end{array}$ & $662(157.2)$ & $722(60.6)$ & $700(55.5)$ & $704(40.3)$ & 0.11 & $2 / 95$ & 0.90 & 0.00 \\
\hline $\begin{array}{l}\text { Mean amplitude of pulse-alone trials } \\
\text { (arbitrary units) }\end{array}$ & $520(133.1)$ & $55 \mid(49.7)$ & $606(55.2)$ & $572(36.4)$ & 0.40 & $2 / 95$ & 0.67 & 0.01 \\
\hline $\begin{array}{l}\text { Percent (\%) early habituation of } \\
\text { pulse-alone trials (between first and } \\
\text { second block) }\end{array}$ & 37.1 (7.4) & $26.8(4.1)$ & $10.5(3.9)$ & $20.6(22.8)$ & 7.10 & $2 / 95$ & $0.001^{c}$ & 0.13 \\
\hline $\begin{array}{l}\text { Percent (\%) total habituation of } \\
\text { pulse-alone trials (between first and } \\
\text { fourth block) }\end{array}$ & $32.0(9.9)$ & $33.5(5.6)$ & $23.9(4.5)$ & $28.9(3.3)$ & 0.96 & $2 / 95$ & 0.39 & 0.02 \\
\hline $\begin{array}{l}\text { Habituation of pulse-alone trials across } \\
4 \text { blocks (linear gradient coefficient } b \text { ) }\end{array}$ & $-61.8(28.8)$ & $-76.9(\mid 3.1)$ & $-58.6(\mid 1.2)$ & $-66.6(8.3)$ & 0.55 & $2 / 95$ & 0.58 & 0.01 \\
\hline
\end{tabular}

Given that the $r$ I 051730 and $r s|3| 7286$ SNPs were in strong linkage disequilibrium $\left(r^{2}=0.97\right)$, the $r s|3| 7286$ data are only shown in Supplementary Table B. British healthy human volunteers grouped according to their CHRNA3 rs 1051730 genotype (mean \pm SEM in parentheses, gender and smoking status in frequency data) ${ }^{a}$ ANCOVA, means adjusted by covariates gender and cigarettes per day.

bonferroni post hoc test: $T$ T $<$ CT \& CC, $p<0.05$.

'Bonferroni post hoc test: $\mathrm{CC}<\mathrm{CT}, \mathrm{p}<0.05 ; \mathrm{CC}<\mathrm{TT}$, $p<0.01$.

were identical, we only reported the results of the rs 1051730 SNP in the main body (for rs1317286 data, see Supplementary Table B). The genotype groups of both SNPs did not differ regarding age, sex, education, smoking status and severity, and startle reactivity (see Table 1 and Supplementary Table B).

Prepulse inhibition was affected by CHRNA3 genotype (see Table 1 and Supplementary Table B, as well as Figure 1a and b). A $3 \times 3$ (SOA condition $\times$ genotype) repeatedmeasures ANCOVA of the rs1051730 SNP with sex and $\mathrm{CPD}$ as covariates revealed significant main effects for the factors: SOA condition $\left(\mathrm{F}(2,90)=16.3 ; p<0.001 ; \eta_{p}^{2}=0.27\right)$, sex $\left(\mathrm{F}(1,91)=14.4 ; p<0.001 ; \eta_{p}^{2}=0.14\right)$, and genotype $\left(\mathrm{F}(2,91)=3.7 ; p<0.05 ; \eta_{p}^{2}=0.08\right)$. Bonferroni post hoc tests revealed that homozygous carriers of the TT allele showed significantly lower PPI levels compared with homozygous carriers of CC allele $(p<0.05$; Cohen's $d=0.79)$ and the heterozygous TC allele carriers $(p<0.05 ; d=0.74)$. Homozygous carriers of CC allele and heterozygous carriers of TC allele did not differ in PPI levels $(d=0.04)$. Analyses of polynominal contrasts across the three genotype groups revealed a significant linear trend $(p<0.01)$ but no significance for a quadratic trend. The analysis of the rs1317286 SNP revealed highly similar results (see Supplementary Table B, ANCOVA statistics and post hoc test are not shown).
The main effect of SOA mirrors the well-known nature of PPI to increase with rising SOA from $30 \mathrm{~ms}$ to $120 \mathrm{~ms}$ (Blumenthal, 1999). The effect of sex reflects the known fact that women have generally lower PPI levels than men (pooled SOA conditions: $\mathrm{F}(1,95)=14.0 ; p<0.001 ; \eta_{p}^{2}=0.15$; Swerdlow et al, 1997).

There was also a significant main effect of CHRNA3 genotype on early habituation (see Table 1 and Supplementary Table B) reflecting a diminishing habituation between the first and the second block of PA trials with increasing load of the rs1051730-C and rs1317286-A alleles (polynominal contrasts: linear trend, $p<0.002$ ).

Age, smoking parameters, and years of education did not correlate with any of the psychophysiological parameters. In particular, neither the Fagerström score nor 'cigarettes per day' were correlated with PPI (see Supplementary Table C).

\section{Bonn Sample (Schizophrenia Patients)}

The CHRNA3 rs 1051730 and rs1317286 SNPs were in complete linkage disequilibrium $\left(r^{2}=1.0\right)$ and both genotype frequencies were distributed in accordance with HWE $\left(\chi^{2}(1)=0.05 ; p=0.82\right)$. The genotype groups did not differ regarding age, sex, education, and smoking status (see Table 2). Within the clinical data, there was a significant main effect of genotype on the number of psychotic 
a

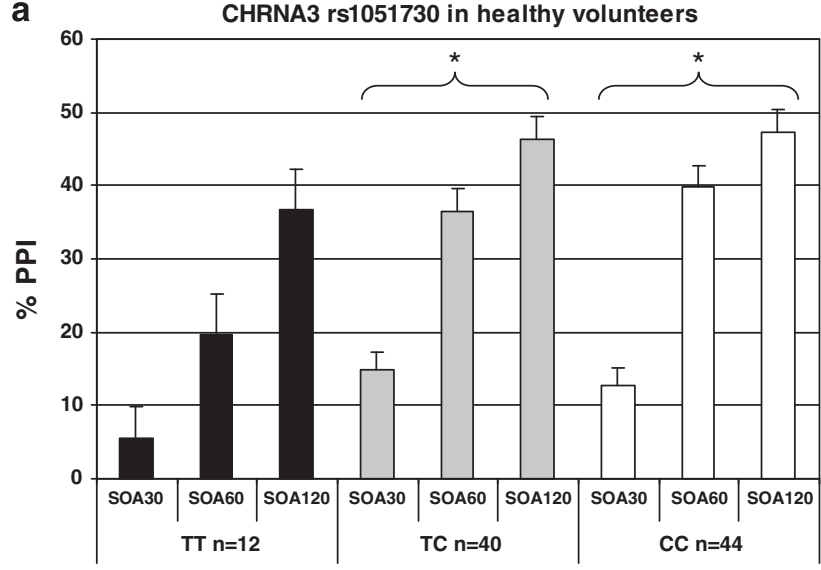

b CHRNA3 rs1317286 in healthy volunteers

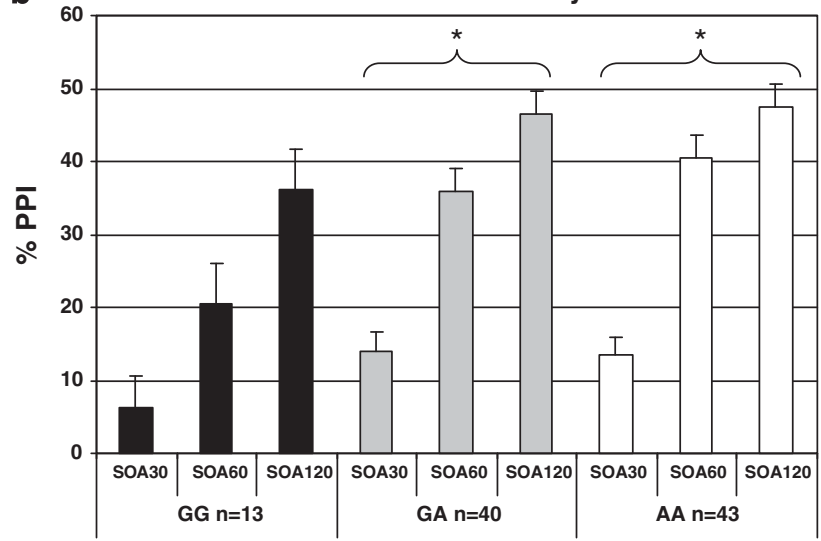

C CHRNA3 rs1051730/rs1317286 in schizophrenia patients

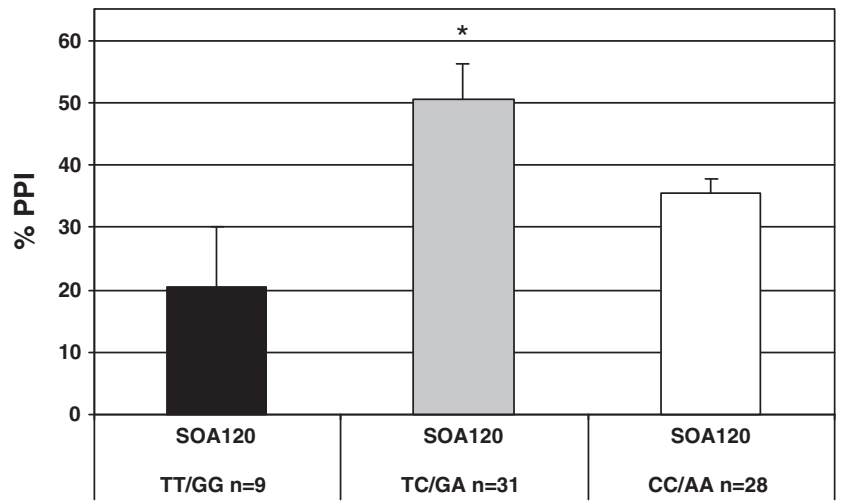

Figure I The effects of CHRNA3 genotype on percent prepulse inhibition (PPI) of the acoustic startle response in healthy human volunteers and schizophrenia patients (means \pm SEM, adjusted for sex and smoking): (a) CHRNA3 rsI05I730 polymorphism in 96 British healthy human volunteers (Bonferroni post hoc test vs TT allele group: ${ }^{*} p<0.05$ ), (b) CHRNA3 rs 1317286 polymorphism in 96 British healthy human volunteers (Bonferroni post hoc test vs GG allele group: ${ }^{*} p<0.05$ ), and (c) the completely associated CHRNA3 rs I05I730 and rs 1317286 polymorphisms in German schizophrenia patients (Bonferroni post hoc test vs TT/GG allele group: $* p<0.05)$

episodes, daily chlorpromazine equivalents, and negative symptoms measured with the PANSS (see Table 2). Homozygous carriers of the TT/GG allele displayed significantly more psychotic episodes than heterozygotes and received significantly higher doses of antipsychotics compared with the two other genotype groups. In contrast, homozygous carriers of the CC/AA allele revealed less negative symptoms than heterozygotes. Further clinical data were not affected by CHRNA3 genotype.

In contrast to all other startle parameters, PPI was again significantly influenced by CHRNA3 genotype (ANCOVA controlled for sex and smoking status (yes/no): $F(2,67)$ $=4.3, p<0.05, \eta_{p}^{2}=0.13$; see Table 2 and Figure $\left.1 \mathrm{c}\right)$. Bonferroni post hoc tests revealed that homozygous carriers of the TT/GG allele displayed significantly lower PPI levels compared with heterozygous carriers of the TC/GA genotype $(p<0.05, d=1.09)$. Both homozygous groups did not significantly differ from each other with respect to PPI; however, the difference showed a moderate effect size $(d=0.55)$. Prepulse inhibition in the CC/AA and the TC/GA group did not differ significantly but again the difference was present with a moderate effect size $(d=0.55)$. Analyses of polynominal contrasts across the three genotype groups revealed a significant quadratic trend $(p<0.01)$ but no significance for a linear trend. If homozygous carriers of TT/GG allele were compared with a merged group of carriers of the C/A allele (TC/GA + CC/AA), both groups differed significantly regarding PPI (ANCOVA controlled for sex and smoking status: $\mathrm{F}(1,64)=3.94, p<0.05$, $\left.\eta_{p}^{2}=0.06\right)$. Further ANCOVAs of the three genotype groups introducing chlorpromazine equivalents, number of psychotic episodes, and PANSS negative symptoms as further covariates still revealed significant main effects for the factor genotype.

Correlational analysis of startle parameter and patient characteristics revealed that age was negatively correlated with startle reactivity (mean amplitude PA trials: $r=-0.38$, $p=0.001$; first block of PA trials: $r=-0.38, p=0.002$ ), indicating that older patients displayed decreased startle reactivity. Moreover, the startle reactivity was negatively associated with the PANSS positive score (mean amplitude PA trials: $r=-0.33, p=0.007$; first block of PA trials: $r=-0.36, p=0.003$ ), negative score (mean amplitude PA trials: $r=-0.37, p=$ n.s.; first block of PA trials: $r=-0.31$, $p=0.01$ ), and total score (mean amplitude PA trials: $r=-0.38, p=0.002$; first block of PA trials: $r=-0.40$, $p=0.001)$. These findings indicate that low startling patients displayed more severe psychotic symptoms. Finally, the number of psychotic episodes was inversely correlated with startle reactivity (mean amplitude PA trials: $r=-0.33, p=0.007$; first block of PA trials: $r=-0.29$, $p=$ n.s.), reflecting that more chronic patients also showed less startle reactivity. Prepulse inhibition did not correlate with any clinical or demographic data. Smoking status was also not correlated with PPI (see Supplementary Table C).

Owing to the methodological differences, German schizophrenia patients and the British controls could not be directly compared regarding startle parameters and PPI. However, in line with many previous studies, the total group of schizophrenia patients displayed significantly decreased PPI levels when compared with an equivalent group of healthy controls $(t(114)=3.2, p<0.003$, controls: $56.9 \%$ PPI (SEM 3.2), $N=46$ ), who were assessed in Bonn with the same PPI paradigm in our previous studies (Quednow et al, 2006b, 2008a). 
Table 2 Demographic Data and Psychophysiological Parameters of German Schizophrenia Patients

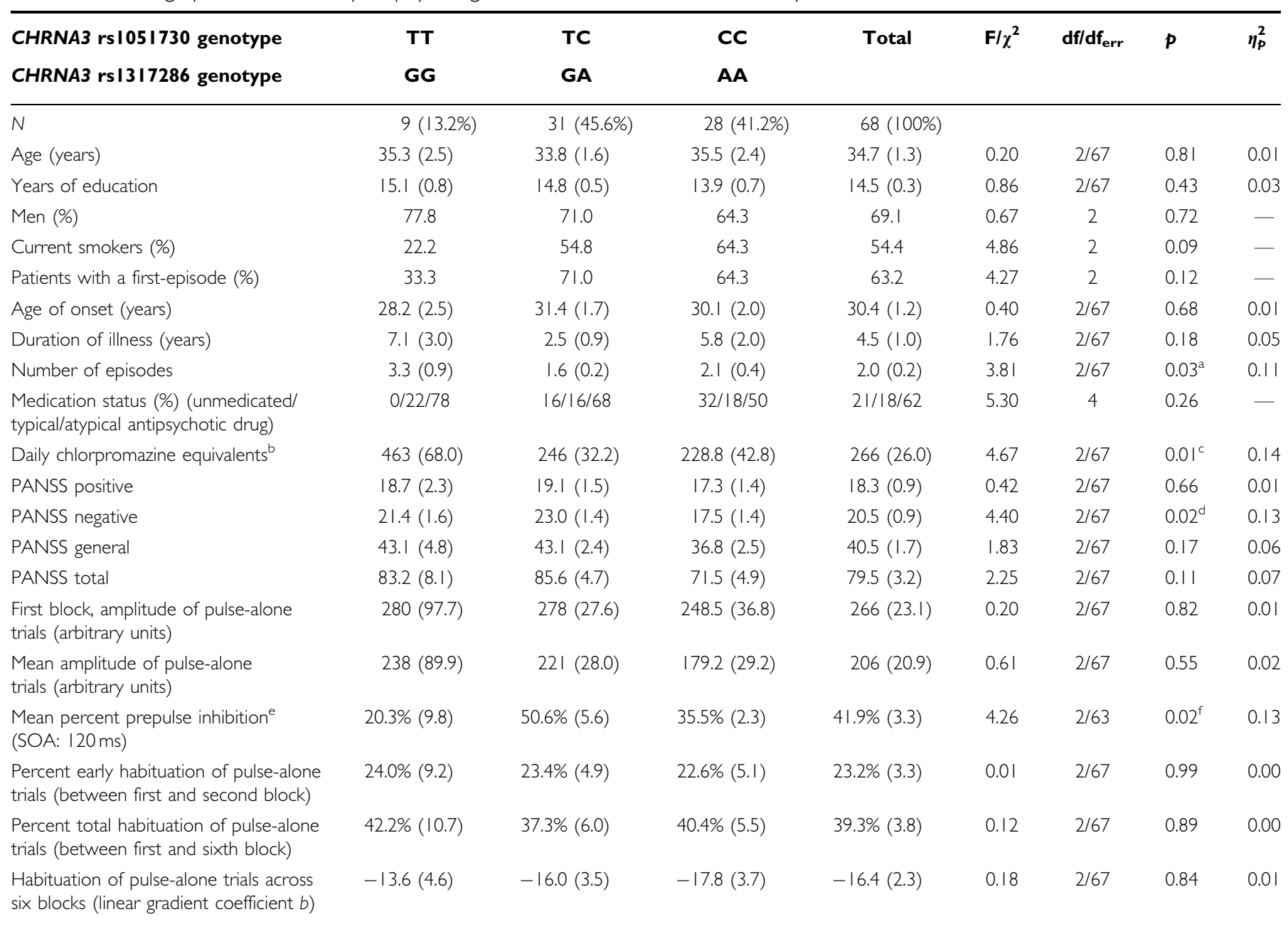

CHRNA3 rs 1051730 and rs 1317286 polymorphisms were in complete linkage disequilibrium.

German schizophrenia patients grouped according to their CHRNA3 rs 051730 and rs I3I7286 genotype (mean \pm SEM values in parentheses, gender and smoking status in frequency data)

äBonferroni post hoc test: TT/GG $>$ TC/GA, $p<0.05$

bUnmedicated patients received the value zero.

'Bonferroni post hoc test: TT/GG $>$ TC/GA \& CC/AA, $p<0.05$.

${ }^{d}$ Bonferroni post hoc test: CC/AA $<$ TC/GA, $p<0.05$.

${ }^{\mathrm{e}} \mathrm{ANCOVA}$, means adjusted by covariates gender and smoking status.

Bonferroni post hoc test: TT/GG $<$ TC/GA, $p<0.05$.

\section{Meta-Analysis of Genotype Effects on Startle Parameter}

To assess the total effect of CHRNA3 genotype on psychophysiological parameters across both samples, we combined the $p$-values in a meta-analytic approach by using Stouffer's $z$-score method (see Table 4). Prepulse inhibition was the only parameter still showing a highly significant effect of genotype $(p=0.0027)$ even after Bonferroni correction for multiple phenotypes.

\section{Association Between CHRNA3 SNPs and Schizophrenia}

There was no association of the tested CHRNA3 SNPs with a diagnosis of schizophrenia per se (Table 3). However, given that the control sample and the patient sample were rather small and have low power to detect common, low-risk variants, and that the samples were recruited in different European countries, this result should not be over interpreted.

\section{DISCUSSION}

This study is, to the best of our knowledge, the first that investigates whether sensorimotor gating depends on polymorphisms in the $\alpha 3$ subunit nAChR gene CHRNA3. We have convincingly demonstrated that the TT genotype of rs 1051730 and the GG genotype of rs1317286 were associated with decreased PPI levels in both healthy volunteers and in schizophrenia patients (combined $p$-value 0.0027). The CHRNA3 rs $1051730 \mathrm{~T}$ allele and $\mathrm{rs} 1317286 \mathrm{G}$ allele have been firmly established as risk alleles for tobacco 
Table 3 Frequencies of CHRNA3 rs 05 I730 and rs/317286 Genotypes

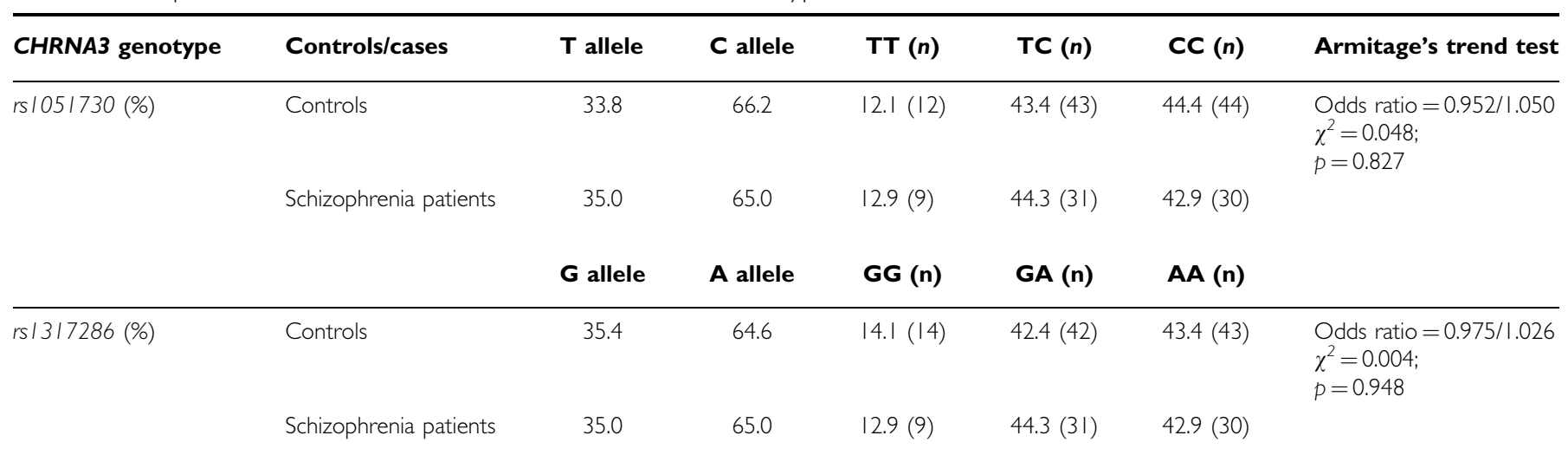

Frequencies of CHRNA3 rs 1051730 and rs 1317286 genotypes in 99 British Caucasian healthy controls and 70 German Caucasian schizophrenia patients (full sample inclusive of cases that dropped out for the electrophysiological analyses due to low startle data quality)

Table 4 Meta-Analysis of CHRNA3 Genotype Effects on Startle Parameters

\begin{tabular}{lccc}
\hline & $\begin{array}{c}\text { London sample } \\
\text { mean } \mathbf{p}^{\mathbf{a}}\end{array}$ & $\begin{array}{c}\text { Bonn } \\
\text { sample } \mathbf{p}\end{array}$ & $\begin{array}{c}\text { Combined } \\
\mathbf{p} \text {-value }\end{array}$ \\
\hline $\begin{array}{l}\text { First block, amplitude } \\
\text { of pulse-alone trials } \\
\begin{array}{l}\text { Mean amplitude of } \\
\text { pulse-alone trials }\end{array}\end{array}$ & 0.95 & 0.82 & 0.97 \\
$\begin{array}{l}\text { Mean percent } \\
\text { prepulse inhibition }\end{array}$ & 0.63 & 0.55 & 0.64 \\
$\begin{array}{l}\text { Percent early } \\
\text { habituation of } \\
\text { pulse-alone trials }\end{array}$ & 0.025 & 0.02 & 0.0027 \\
$\begin{array}{l}\text { Percent total } \\
\text { habituation of } \\
\text { pulse-alone trials } \\
\text { Habituation slope of } \\
\text { pulse-alone trials }(b)\end{array}$ & 0.37 & 0.99 & 0.15 \\
\hline
\end{tabular}

Meta-analysis performed across both investigated samples (London healthy volunteers $(n=96)$ and Bonn schizophrenia patients $(n=68))$

${ }^{a}$ Averaged between rs 1051730 and rs 1317286 genotype.

'Stouffer's z-score method.

dependence (Berrettini et al, 2008; Bierut et al, 2008; Caporaso et al, 2009; Saccone et al, 2009). In our patients, these CHRNA3 SNPs were also associated with number of previous psychotic episodes, daily chlorpromazine dose, and negative symptoms - all indicators for severity of the illness. Thus, further investigation of the CHRNA3 SNPs regarding risk, course, and treatment of schizophrenia in larger samples is warranted. There was no indication of an association with schizophrenia per se, but the sample size and design of this study obviously do not allow drawing conclusions from that. To the best of our knowledge, there are no published studies that have investigated CHRNA3/ CHRNA5 gene variants for association with schizophrenia (http://www.schizophreniaforum.org/res/sczgene; Allen et al, 2008), despite the location of these genes within a region on chromosome $15 \mathrm{q}$ possibly linked with schizophrenia (Lewis et al, 2003). The demonstration in this study that CHRNA3 gene variants are associated with an established endophenotype of schizophrenia might motivate a closer look at these genes in large-scale association studies of schizophrenia. Moreover, we initially found a significant CHRNA3 effect on early habituation in the London sample, but this effect could not be replicated in the Bonn sample. In the combined analysis of both samples (Table 4), we did not find an overall effect of CHRNA3 genotype on any habituation measure.

At which level of the brain might mutations in the $\alpha 3$ nAChR subunits affect PPI? $\alpha 3$ nAChR mRNA is expressed in high densities in the prefrontal cortex (PFC), the motor and the entorhinal cortex, and in different nuclei of the thalamus, and in lower densities also throughout the hippocampus (Gotti and Clementi, 2004; Paterson and Nordberg, 2000) - all structures that are also implicated in the mediation of PPI (Koch, 1999; Swerdlow et al, 2001). Moreover, there is evidence that $\alpha 3 \mathrm{nAChR}$ subunits regulate dopamine neurotransmission in the striatum (Quik et al, 2005; Salminen et al, 2004), which is a key element of the CSPP circuitry (Koch, 1999; Swerdlow et al, 2001). Thus, the effects of CHRNA3 genotype on PPI could be either direct within the CSPP circuitry or indirect via the striatal dopamine system.

Our findings support the view that the cholinergic system has a key role in pre-attentional and attentional mechanisms. Recent evidence indicates that the cholinergic system has an integrating or synchronizing function in the central nervous system, especially in the PFC (Mansvelder et al, 2009). nAChRs seem to function as gatekeepers in neural transmission as pre-synaptic nAChRs tune inhibitory and excitatory inputs of the neuron (Mansvelder et al, 2009). This is true for modulating glutamatergic transmission (Vidal and Changeux, 1993) and for dopaminergic neurotransmission (Salminen et al, 2004), both of which are relevant for PPI (Koch, 1999; Swerdlow et al, 2001).

Our study showed that PPI is likely to be mediated by the $\alpha 3$ subunit of the nAChR, and the results of the mecamylamine study by George and colleagues (2006) 
would be consistent with that. Given that schizophrenia patients display PPI deficits, that PPI and symptom severity are modulated by CHRNA3 polymorphisms, and that the nAChR system is an important neuromodulator, a future promising target of schizophrenia research might be the development of new medications for treating schizophrenia or at least cognitive deficits in schizophrenia, which affect the $\alpha 3$ subunits of the nAChR in the central nervous system. It is possible that abnormally reactive cholinergic responsivity is sufficient to cause an altered dopaminergic transmission (Briand et al, 2007), hence stabilizing the cholinergic system should also regulate the dopaminergic system that is well-known to be affected in schizophrenia (Howes and Kapur, 2009).

A measure of sensory gating is the suppression of the auditory-evoked potential P50 response to repeated stimuli (for a review, see Turetsky et al, 2007). Both P50 suppression and PPI are modulated by the nAChR agonist, nicotine, which suggests that brain cholinergic systems are involved in gating processes common to both paradigms (Turetsky et al, 2007). However, sensory gating measured by P50 suppression and sensorimotor gating measured by PPI seem to be largely independent phenomena because they are not correlated (Braff et al, 2007; Oranje et al, 2006; Schwarzkopf et al, 1993). Our results further support that P50 suppression and PPI are likely to be two different inhibitory mechanisms. Although P50 suppression seems to depend on $\alpha 7$ subunits of the nAChR (Freedman et al, 1997), PPI is very likely to be influenced by $\alpha 3 \mathrm{nAChR}$ functioning as shown here. Animal studies further support this hypothesis: $\alpha 7 \mathrm{nAChR}$ knock-out mice exhibit normal PPI levels and neither selective $\alpha 7 \mathrm{nAChR}$ agonists (GTS-21 and AR-R-17779) nor a selective $\alpha 7$ nAChR antagonist (methyllycaconitine) altered PPI level in rodents (Schreiber et al, 2002; Suemaru et al, 2004). On the basis of the seminal findings of Freedman et al (1997), $\alpha 7$ agonists were suggested as cognitive enhancer in schizophrenia, but the a7 nAChR partial agonist, DMXB, failed to improve cognitive deficits is schizophrenia in a recent clinical trial (Freedman et al, 2008). However, $\alpha 7$ and $\alpha 4 \beta 2 \mathrm{nAChRs}$ developed receptor insensitivity (tachyphylaxis) if there were repeatedly stimulated (Kuryatov et al, 2000), making these receptors less suitable targets for a continuous drug treatment (Harvey, 2009). In contrast, other nAChRs, including the $\alpha 3$ subunit, are largely resistant to inactivation after repeated stimulation (Kuryatov et al, 2000) and, thus, $\alpha 3$ subunits of the $\mathrm{nAChR}$ might be more promising targets for potential cognitive enhancers in schizophrenia.

Interestingly, effects of specific pharmacological challenges on PPI in rodents have been replicated in human genetic studies. Previously, it was consistently shown that dopaminergic, serotonergic, glutamatergic, and acetylcholinergic challenges have an impact on PPI in rodents (for review, see Geyer et al, 2001). In recent years, it was demonstrated that polymorphisms within the human dopamine and serotonin systems affect PPI (Quednow et al, 2008b, c, 2009; Roussos et al, 2008a, b). This study extends these findings to the nAChR system, as we have clearly shown that SNPs within the $\alpha 3$ subunit of the $\mathrm{nAChR}$ also influence PPI in humans. Thus, these recent developments predict that polymorphisms within the glutamatergic system might also explain a portion of the PPI variance in the population.
One limitation of this study is that the two independent samples were assessed using slightly different PPI paradigms. This precludes a comparison of the genetic effects on PPI between samples. However, the replication across samples and study sites despite some procedural differences underscores the robustness of our findings. A second limitation is that we did not assess severity of smoking behavior in the schizophrenia sample assessed in Bonn. However, in contrast to some previous studies (Duncan et al, 2001; Swerdlow et al, 2006), the method that we used in Bonn was less susceptible to the effects of smoking status on PPI, whereas it was proven sensitive to psychopathological modulations of PPI (Quednow et al, 2006a, b, c, 2008a,b). This might have two reasons: (1) smoking withdrawal can decrease PPI (George et al, 2006; Kumari and Gray, 1999), but our subjects were allowed to smoke ad libitum before testing; (2) heavy smokers with schizophrenia display higher PPI levels than light- or non-smoking patients (Swerdlow et al, 2006), which is in line with the finding that nicotine itself could enhance PPI (Kumari et al, 1997; Postma et al, 2006). As we did not assess smoking severity, the effect of smoking status alone was possibly too small to detect in our sample. Moreover, the investigation of smoking $\times$ genotype associations was not the main focus of this study. Thus, we believe that the lack of detailed smoking data in the schizophrenia sample does not impair our main results presented here. A further minor limitation is that the low number of smokers in the London healthy controls did not allow for separate analyses of CHRNA3 genotype effects on PPI in smokers and nonsmokers. Thus, the power to assess smoking status effects on PPI, as a function of CHRNA3 genotype, was restricted because of the small number of smokers in the healthy controls (and the limited sample size in the schizophrenia sample). However, controlling for smoking status in statistical analyses, and excluding the 23 smokers in the British healthy volunteers did not alter the results (genotype effect on PPI (corrected for gender): rs1051730: $\mathrm{F}(2,69)=3.98$; $p<0.05 ; \quad \eta_{p}^{2}=0.10 ; \quad$ rs1317286: $\quad \mathrm{F}(2,69)=4.28 ; \quad p<0.05 ;$ $\eta_{p}^{2}=0.11$ ), suggesting that the reported association is not mediated or confounded by current nicotine use. In addition, 17 of the 23 smokers had a Fagerström score of $0-2$, reflecting very low addiction in most of the smoking healthy controls. Future studies might systematically investigate the interaction of chronic smoking and acute nicotine administration with genetic polymorphisms in their effect on sensory gating and attentional functions. Extending the self-medication hypothesis, we would hypothesize stronger nicotine effects on PPI in carriers of gene variants associated with smoking or with schizophrenia. Finally, we have only investigated two SNPs of the $\alpha 3$ subunits of the nAChR. Hence, mutations in other subunits and of $\mathrm{nAChR}$ haplotypes should be examined in future studies.

One might be surprised that we did not replicate the association of smoking severity and CHRNA3 genotype (Berrettini et al, 2008; Bierut et al, 2008; Caporaso et al, 2009; Saccone et al, 2009). However, recent studies showing an association of smoking behavior with CHRNA3 genotype all included relatively strong smokers (eg, Caporaso et al, 2009: 18.5-22.0 CPD), whereas we had only seven smokers in the total healthy control sample $(n=96)$ that smoked 
more than 15 cigarettes per day. Moreover, in the schizophrenia sample, we did not assess smoking severity and none of the previous studies reported an association of smoking status per se and CHRNA genotype. Lastly, in contrast to the previous association studies on smoking and CHRNA3, we have investigated relatively small samples, indicating that the CHRNA effect on PPI seems to be much greater than on smoking severity. Thus, our samples were not ideal for testing smoking $\times$ CHRNA3 genotype associations, which was, however, also not the focus of our study.

In conclusion, our results confirmed previous pharmacological studies that proposed an impact of the nAChR system on sensorimotor gating. We have observed that polymorphisms of the $\alpha 3$ subunits of the nAChR explained approximately $8-13 \%$ of the PPI variance in two independent samples, suggesting a major role of $\alpha 3$ subunits of the $\mathrm{nAChR}$ in the mediation of PPI. Finally, $\alpha 3$-containing nAChRs might be explored as a new pharmacological target for cognitive enhancement in patients with schizophrenia.

\section{ACKNOWLEDGEMENTS}

NP and MW are supported by German Research Foundation (DFG, Grant No. WA 737/7). BBQ is supported by the Swiss National Science Foundation (Grant No. PP00P1_123516). UE is supported by the DFG (Grant No. ET 31/2-1). DAC, UE, and AS were supported by the European Commission (Grant No. FP6-2005-LIFESCI HEALTH-7 STREP project 037,761, SGENE). VK was supported by the Wellcome Trust (067427/z/02). RM was supported by the German Federal Ministry of Education and Research (BMBF; Grant No. 01GV0907). We thank $\mathrm{V}$ Guttenthaler and A Petruschke for expert technical assistance. Mundipharma (Basel, Switzerland) contributed additional funding. Experimental design, data acquisition, statistical analyses, and interpretation of the results were conducted without input from any pharmaceutical company.

\section{DISCLOSURE}

The authors declare no conflict of interest.

\section{REFERENCES}

Acri JB, Brown KJ, Saah MI, Grunberg NE (1995). Strain and age differences in acoustic startle responses and effects of nicotine in rats. Pharmacol Biochem Behav 50: 191-198.

Acri JB, Morse DE, Popke EJ, Grunberg NE (1994). Nicotine increases sensory gating measured as inhibition of the acoustic startle reflex in rats. Psychopharmacology (Berl) 114: 369-374.

Allen NC, Bagade S, McQueen MB, Ioannidis JP, Kavvoura FK, Khoury MJ et al (2008). Systematic meta-analyses and field synopsis of genetic association studies in schizophrenia: the SzGene database. Nat Genet 40: 827-834.

Anokhin AP, Heath AC, Myers E, Ralano A, Wood S (2003). Genetic influences on prepulse inhibition of startle reflex in humans. Neurosci Lett 353: 45-48.

Baschnagel JS, Hawk Jr LW (2008). The effects of nicotine on the attentional modification of the acoustic startle response in nonsmokers. Psychopharmacology (Berl) 198: 93-101.
Berrettini W, Yuan X, Tozzi F, Song K, Francks C, Chilcoat H et al (2008). Alpha-5/alpha-3 nicotinic receptor subunit alleles increase risk for heavy smoking. Mol Psychiatry 13: 368-373.

Bierut LJ, Stitzel JA, Wang JC, Hinrichs AL, Grucza RA, Xuei X et al (2008). Variants in nicotinic receptors and risk for nicotine dependence. Am J Psychiatry 165: 1163-1171.

Blumenthal TD (1999). Short lead interval startle modification. In: Dawson ME, Schell AM, Böhmelt AH (eds). Startle Modification. Implications for Neuroscience, Cognitive Sciences, and Clinical Science. Cambridge University Press: Cambridge. pp 51-71.

Braff D, Stone C, Callaway E, Geyer M, Glick I, Bali L (1978). Prestimulus effects on human startle reflex in normals and schizophrenics. Psychophysiology 15: 339-343.

Braff DL, Freedman R (2002). Endophenotypes in studies of the genetics of schizophrenia. In: Davis KL, Charney D, Coyle JT, Nemeroff C (eds). Neuropsychopharmacology: The Fifth Generation of Progress. American College of Neuropsychopharmacology: Nashville, TN, pp 703-716.

Braff DL, Geyer MA, Swerdlow NR (2001). Human studies of prepulse inhibition of startle: normal subjects, patient groups, and pharmacological studies. Psychopharmacology (Berl) 156: 234-258.

Braff DL, Grillon C, Geyer MA (1992). Gating and habituation of the startle reflex in schizophrenic patients. Arch Gen Psychiatry 49: 206-215.

Braff DL, Light GA, Swerdlow NR (2007). Prepulse inhibition and P50 suppression are both deficient but not correlated in schizophrenia patients. Biol Psychiatry 61: 1204-1207.

Briand LA, Gritton H, Howe WM, Young DA, Sarter M (2007). Modulators in concert for cognition: modulator interactions in the prefrontal cortex. Prog Neurobiol 83: 69-91.

Cadenhead KS, Geyer MA, Braff DL (1993). Impaired startle prepulse inhibition and habituation in patients with schizotypal personality disorder. Am J Psychiatry 150: 1862-1867.

Cadenhead KS, Swerdlow NR, Shafer KM, Diaz M, Braff DL (2000). Modulation of the startle response and startle laterality in relatives of schizophrenic patients and in subjects with schizotypal personality disorder: evidence of inhibitory deficits. Am J Psychiatry 157: 1660-1668.

Caporaso N, Gu F, Chatterjee N, Sheng-Chih J, Yu K, Yeager M et al (2009). Genome-wide and candidate gene association study of cigarette smoking behaviors. PLoS One 4: e4653.

Curzon P, Kim DJ, Decker MW (1994). Effect of nicotine, lobeline, and mecamylamine on sensory gating in the rat. Pharmacol Biochem Behav 49: 877-882.

Dalack GW, Healy DJ, Meador-Woodruff JH (1998). Nicotine dependence in schizophrenia: clinical phenomena and laboratory findings. Am J Psychiatry 155: 1490-1501.

Della Casa V, Hofer I, Weiner I, Feldon J (1998). The effects of smoking on acoustic prepulse inhibition in healthy men and women. Psychopharmacology (Berl) 137: 362-368.

Duncan E, Madonick S, Chakravorty S, Parwani A, Szilagyi S, Efferen T et al (2001). Effects of smoking on acoustic startle and prepulse inhibition in humans. Psychopharmacology (Berl) 156: 266-272.

Faraday MM, O'Donoghue VA, Grunberg NE (1999). Effects of nicotine and stress on startle amplitude and sensory gating depend on rat strain and sex. Pharmacol Biochem Behav 62: 273-284.

Faraday MM, Rahman MA, Scheufele PM, Grunberg NE (1998). Nicotine administration impairs sensory gating in Long-Evans rats. Pharmacol Biochem Behav 61: 281-289.

Faul F, Erdfelder E, Lang AG, Buchner A (2007). G*Power 3: a flexible statistical power analysis program for the social, behavioral, and biomedical sciences. Behav Res Methods 39: 175-191.

Freedman R, Coon H, Myles-Worsley M, Orr-Urtreger A, Olincy A, Davis A et al (1997). Linkage of a neurophysiological deficit in 
schizophrenia to a chromosome 15 locus. Proc Natl Acad Sci USA 94: 587-592.

Freedman R, Olincy A, Buchanan RW, Harris JG, Gold JM, Johnson L et al (2008). Initial phase 2 trial of a nicotinic agonist in schizophrenia. Am J Psychiatry 165: 1040-1047.

George TP, Termine A, Sacco KA, Allen TM, Reutenauer E, Vessicchio JC et al (2006). A preliminary study of the effects of cigarette smoking on prepulse inhibition in schizophrenia: involvement of nicotinic receptor mechanisms. Schizophr Res 87: 307-315.

Geyer MA, Krebs-Thomson K, Braff DL, Swerdlow NR (2001). Pharmacological studies of prepulse inhibition models of sensorimotor gating deficits in schizophrenia: a decade in review. Psychopharmacology (Berl) 156: 117-154.

Gottesman II, Gould TD (2003). The endophenotype concept in psychiatry: etymology and strategic intentions. Am J Psychiatry 160: 636-645.

Gotti C, Clementi F (2004). Neuronal nicotinic receptors: from structure to pathology. Prog Neurobiol 74: 363-396.

Graham FK (1975). The more or less startling effects of weak prestimulation. Psychophysiology 12: 238-248.

Greenwood TA, Braff DL, Light GA, Cadenhead KS, Calkins ME, Dobie DJ et al (2007). Initial heritability analyses of endophenotypic measures for schizophrenia: the consortium on the genetics of schizophrenia. Arch Gen Psychiatry 64: 1242-1250.

Harvey PD (2009). Pharmacological cognitive enhancement in schizophrenia. Neuropsychol Rev 19: 324-335.

Heatherton TF, Kozlowski LT, Frecker RC, Fagerstrom KO (1991). The Fagerstrom test for nicotine dependence: a revision of the Fagerstrom tolerance questionnaire. $\mathrm{Br} J$ Addict 86: 1119-1127.

Hong LE, Wonodi I, Lewis J, Thaker GK (2008). Nicotine effect on prepulse inhibition and prepulse facilitation in schizophrenia patients. Neuropsychopharmacology 33: 2167-2174.

Howes OD, Kapur S (2009). The dopamine hypothesis of schizophrenia: version III-the final common pathway. Schizophr Bull 35: 549-562.

International HapMap Consortium (2003). The international HapMap project. Nature 426: 789-796.

Kay SR, Opler LA, Fiszbein A (1992). Positive and Negative Syndrome Scale (PANSS). Manual. Multi-Health Systems: North Tonawanda, NY.

Koch M (1999). The neurobiology of startle. Prog Neurobiol 59: 107-128.

Kumari V, Antonova E, Zachariah E, Galea A, Aasen I, Ettinger U et al (2005a). Structural brain correlates of prepulse inhibition of the acoustic startle response in healthy humans. Neuroimage 26: $1052-1058$.

Kumari V, Checkley SA, Gray JA (1996). Effect of cigarette smoking on prepulse inhibition of the acoustic startle reflex in healthy male smokers. Psychopharmacology (Berl) 128: 54-60.

Kumari V, Cotter PA, Checkley SA, Gray JA (1997). Effect of acute subcutaneous nicotine on prepulse inhibition of the acoustic startle reflex in healthy male non-smokers. Psychopharmacology (Berl) 132: 389-395.

Kumari V, Das M, Zachariah E, Ettinger U, Sharma T (2005b). Reduced prepulse inhibition in unaffected siblings of schizophrenia patients. Psychophysiology 42: 588-594.

Kumari V, Gray JA (1999). Smoking withdrawal, nicotine dependence and prepulse inhibition of the acoustic startle reflex. Psychopharmacology (Berl) 141: 11-15.

Kumari V, Postma P (2005). Nicotine use in schizophrenia: the self medication hypotheses. Neurosci Biobehav Rev 29: 1021-1034.

Kumari V, Soni W, Mathew VM, Sharma T (2000). Prepulse inhibition of the startle response in men with schizophrenia: effects of age of onset of illness, symptoms, and medication. Arch Gen Psychiatry 57: 609-614.
Kuryatov A, Olale FA, Choi C, Lindstrom J (2000). Acetylcholine receptor extracellular domain determines sensitivity to nicotineinduced inactivation. Eur J Pharmacol 393: 11-21.

Lewis CM, Levinson DF, Wise LH, DeLisi LE, Straub RE, Hovatta I et al (2003). Genome scan meta-analysis of schizophrenia and bipolar disorder, part II: schizophrenia. Am J Hum Genet 73: 34-48.

Ludewig K, Geyer MA, Vollenweider FX (2003). Deficits in prepulse inhibition and habituation in never-medicated, firstepisode schizophrenia. Biol Psychiatry 54: 121-128.

Mansvelder HD, Mertz M, Role LW (2009). Nicotinic modulation of synaptic transmission and plasticity in cortico-limbic circuits. Semin Cell Dev Biol 20: 432-440.

Oranje B, Geyer MA, Bocker KB, Leon Kenemans J, Verbaten MN (2006). Prepulse inhibition and P50 suppression: commonalities and dissociations. Psychiatry Res 143: 147-158.

Papke RL, Sanberg PR, Shytle RD (2001). Analysis of mecamylamine stereoisomers on human nicotinic receptor subtypes. J Pharmacol Exp Ther 297: 646-656.

Parwani A, Duncan EJ, Bartlett E, Madonick SH, Efferen TR, Rajan $\mathrm{R}$ et al (2000). Impaired prepulse inhibition of acoustic startle in schizophrenia. Biol Psychiatry 47: 662-669.

Paterson D, Nordberg A (2000). Neuronal nicotinic receptors in the human brain. Prog Neurobiol 61: 75-111.

Perry W, Feifel D, Minassian A, Bhattacharjie I, Braff DL (2002). Information processing deficits in acutely psychotic schizophrenia patients medicated and unmedicated at the time of admission. Am J Psychiatry 159: 1375-1381.

Postma P, Gray JA, Sharma T, Geyer M, Mehrotra R, Das M et al (2006). A behavioural and functional neuroimaging investigation into the effects of nicotine on sensorimotor gating in healthy subjects and persons with schizophrenia. Psychopharmacology (Berl) 184: 589-599.

Quednow BB (2008). Sensorimotor gating deficits in psychiatric disorders. J Neuropsychol 19: 139-163.

Quednow BB, Frommann I, Berning J, Kuhn KU, Maier W, Wagner M (2008a). Impaired sensorimotor gating of the acoustic startle response in the prodrome of schizophrenia. Biol Psychiatry 64: 766-773.

Quednow BB, Kuhn KU, Beckmann K, Westheide J, Maier W, Wagner M (2006a). Attenuation of the prepulse inhibition of the acoustic startle response within and between sessions. Biol Psychol 71: 256-263.

Quednow BB, Kuhn KU, Mossner R, Schwab SG, Schuhmacher A, Maier W et al (2008b). Sensorimotor gating of schizophrenia patients is influenced by 5-HT2A receptor polymorphisms. Biol Psychiatry 64: 434-437.

Quednow BB, Schmechtig A, Ettinger U, Petrovsky N, Collier DA, Vollenweider FX et al (2009). Sensorimotor gating depends on polymorphisms of the serotonin-2A receptor and catechol-Omethyltransferase, but not on neuregulin-1 Arg38Gln genotype: a replication study. Biol Psychiatry 66: 614-620.

Quednow BB, Wagner M, Mossner R, Maier W, Kuhn KU (2008c). Sensorimotor gating of schizophrenia patients depends on catechol-O-methyltransferase Val158Met polymorphism. Schizophr Bull (in press).

Quednow BB, Wagner M, Westheide J, Beckmann K, Bliesener N, Maier W et al (2006b). Sensorimotor gating and habituation of the startle response in schizophrenic patients randomly treated with amisulpride or olanzapine. Biol Psychiatry 59: 536-545.

Quednow BB, Westheide J, Kuhn KU, Werner P, Maier W, Hawellek B et al (2006c). Normal prepulse inhibition and habituation of acoustic startle response in suicidal depressive patients without psychotic symptoms. J Affect Disord 92: 299-303.

Quik M, Vailati S, Bordia T, Kulak JM, Fan H, McIntosh JM et al (2005). Subunit composition of nicotinic receptors in monkey 
striatum: effect of treatments with 1-methyl-4-phenyl-1,2,3,6tetrahydropyridine or L-DOPA. Mol Pharmacol 67: 32-41.

Ripoll N, Bronnec M, Bourin M (2004). Nicotinic receptors and schizophrenia. Curr Med Res Opin 20: 1057-1074.

Roussos P, Giakoumaki SG, Bitsios P (2008a). The dopamine D(3) receptor Ser9Gly polymorphism modulates prepulse inhibition of the acoustic startle reflex. Biol Psychiatry 64: 235-240.

Roussos P, Giakoumaki SG, Rogdaki M, Pavlakis S, Frangou S, Bitsios P (2008b). Prepulse inhibition of the startle reflex depends on the catechol-O-methyltransferase Val158Met gene polymorphism. Psychol Med 38: 1651-1658.

Sacco KA, Termine A, Seyal A, Dudas MM, Vessicchio JC, Krishnan-Sarin S et al (2005). Effects of cigarette smoking on spatial working memory and attentional deficits in schizophrenia: involvement of nicotinic receptor mechanisms. Arch Gen Psychiatry 62: 649-659.

Saccone NL, Saccone SF, Hinrichs AL, Stitzel JA, Duan W, Pergadia ML et al (2009). Multiple distinct risk loci for nicotine dependence identified by dense coverage of the complete family of nicotinic receptor subunit $(C H R N)$ genes. Am J Med Genet B Neuropsychiatr Genet 150B: 453-466.

Salminen O, Murphy KL, McIntosh JM, Drago J, Marks MJ, Collins $\mathrm{AC}$ et al (2004). Subunit composition and pharmacology of two classes of striatal presynaptic nicotinic acetylcholine receptors mediating dopamine release in mice. Mol Pharmacol 65: $1526-1535$.

Schreiber R, Dalmus M, De Vry J (2002). Effects of alpha 4/beta 2and alpha 7-nicotine acetylcholine receptor agonists on prepulse inhibition of the acoustic startle response in rats and mice. Psychopharmacology (Berl) 159: 248-257.

Schwarzkopf SB, Lamberti JS, Smith DA (1993). Concurrent assessment of acoustic startle and auditory P50 evoked potential measures of sensory inhibition. Biol Psychiatry 33: 815-828.

Spielewoy C, Markou A (2004). Strain-specificity in nicotine attenuation of phencyclidine-induced disruption of prepulse inhibition in mice: relevance to smoking in schizophrenia patients. Behav Genet 34: 343-354.

Suemaru K, Yasuda K, Umeda K, Araki H, Shibata K, Choshi T et al (2004). Nicotine blocks apomorphine-induced disruption of prepulse inhibition of the acoustic startle in rats: possible involvement of central nicotinic alpha7 receptors. Br J Pharmacol 142: 843-850.

Swerdlow NR, Geyer MA, Braff DL (2001). Neural circuit regulation of prepulse inhibition of startle in the rat: current knowledge and future challenges. Psychopharmacology (Berl) 156: 194-215.

Swerdlow NR, Hartman PL, Auerbach PP (1997). Changes in sensorimotor inhibition across the menstrual cycle: implications for neuropsychiatric disorders. Biol Psychiatry 41: 452-460.

Swerdlow NR, Light GA, Cadenhead KS, Sprock J, Hsieh MH, Braff DL (2006). Startle gating deficits in a large cohort of patients with schizophrenia: relationship to medications, symptoms, neurocognition, and level of function. Arch Gen Psychiatry 63: 1325-1335.

Turetsky BI, Calkins ME, Light GA, Olincy A, Radant AD, Swerdlow NR (2007). Neurophysiological endophenotypes of schizophrenia: the viability of selected candidate measures. Schizophr Bull 33: 69-94.

Vidal C, Changeux JP (1993). Nicotinic and muscarinic modulations of excitatory synaptic transmission in the rat prefrontal cortex in vitro. Neuroscience 56: 23-32.

Whitlock MC (2005). Combining probability from independent tests: the weighted $z$-method is superior to Fisher's approach. J Evol Biol 18: 1368-1373.

Supplementary Information accompanies the paper on the Neuropsychopharmacology website (http://www.nature.com/npp) 